nintedanib versus placebo in patients with SSc-ILD were investigated in the SENSCIS trial (NCT02597933).

Objectives: To characterise GI AEs associated with nintedanib therapy in the SENSCIS trial.

Methods: Patients with SSc-ILD with onset of first non-Raynaud symptom $<7$ years were randomised to receive nintedanib $150 \mathrm{mg}$ bid or placebo double-blind. Dose reductions to $100 \mathrm{mg}$ bid and treatment interruptions were allowed to manage adverse events. AEs reported over 52 weeks of treatment were coded using preferred terms in the Medical Dictionary for Regulatory Activities and analysed descriptively. A questionnaire was used to collect additional information on diarrhoea AEs.

Results: A total of 576 patients (288 per group) received $\geq 1$ dose of nintedanib or placebo. Over 52 weeks, $13.9 \%$ and $7.3 \%$ of patients treated with nintedanib and placebo discontinued study treatment due to AEs. The most frequent $\mathrm{AEs}$ in patients treated with nintedanib were diarrhoea $(75.7 \%$ vs $31.6 \%)$, nausea $(31.6 \%$ vs $13.5 \%)$ and vomiting $(24.7 \%$ vs $10.4 \%)$. Serious diarrhoea AEs were reported in 2 patients $(0.7 \%)$ in each group, and serious vomiting AEs were reported in 2 patients $(0.7 \%)$ in the placebo group and none in the nintedanib group. Of the 218 nintedanib-treated patients who experienced a diarrhoea $A E$, most experienced events that were at worst of mild $(49.5 \%)$ or moderate $(45.0 \%)$ intensity, most $(70.2 \%)$ experienced 1 or 2 events, and the duration of diarrhoea AEs was $\leq 9$ days for $50 \%$ of the events reported over 52 weeks. Among nintedanib-treated patients who experienced $\geq 1$ diarrhoea $\mathrm{AE}, 26.1 \%$ had a permanent dose reduction and $9.2 \%$ discontinued study drug due to the AE. Among the 91 patients in the placebo group who experienced $>1$ diarrhoea $A E$, the duration of diarrhoea $A E s$ was $\leq 3$ days for $50 \%$ of the events reported over 52 weeks, $2.2 \%$ had a permanent dose reduction and $1.1 \%$ discontinued study drug due to the AE.

Conclusion: In patients with SSc-ILD, the gastrointestinal AEs associated with nintedanib were manageable for most patients and consistent with its known safety and tolerability profile in patients with IPF.

Disclosure of Interests: Toby Maher Grant/research support from: Received funds from $\mathrm{BI}$ advisory board participation and conference travel. Received research funding and/or consulting fees or other remuneration from GSK, UCB, AstraZeneca, Roche, Bayer, Biogen Idec, Cipla, Prometic, and Sanumed. Toby Maher has, via his institution, received industry-academic funding from GlaxoSmithKline R\&D and UCB., Consultant for: Toby Maher has received consultancy or speakers fees from Apellis, AstraZeneca, Bayer, Biogen Idec, Boehringer Ingelheim, Galapagos, GlaxoSmithKline R\&D, Indalo, Pliant, ProMetic, Roche, Samumed and UCB; and has received consultancy fees from Galecto., Kristin Highland Grant/research support from: Kristin Highland is a site PI for the SENSCIS trial (Dr Highland's institution has the contract for the study) which is funded by Boehringer Ingelheim., Consultant for: Kristin Highland is a paid consultant for Boehringer Ingelheim through her role sitting on the steering committee., Speakers bureau: Kristin Highland is on the speakers' bureau for Boehringer Ingelheim., Martina Gahlemann Employee of: Employee of Boehringer Ingelheim, Arata Azuma Consultant for: Arata Azuma has received personal fees from Boehringer Ingelheim, Shionogi \& Co., Ltd, Taiho Pharmaceutical Co., Ltd, and Asahikasei Pharma Co., Aryeh Fischer Grant/research support from: Aryeh Fischer has received a grant from Boehringer Ingelheim (Consultant/steering committee member/ principal investigator on clinical trials)., Consultant for: Aryeh Fischer has received personal fees from Boehringer Ingelheim (Consultant/steering committee member/principal investigator on clinical trials), GenentechRoche (Consultant/steering committee member/principal investigator on clinical trials), Pfizer (Consultant) and Genentech (Consultant)., Maureen Mayes Grant/research support from: Maureen Mayes is a clinical trial investigator for Boehringer-Ingelheim; Galapagos, Reata, Sanofi, MerckSerono, Consultant for: Maureen Mayes is a member of scientific advisory boards for Galapagos NV (Pharma), Boehringer-Ingelheim, MitsubishiTanabe, Astellas: Grant Review Board for Actelion., Speakers bureau: Maureen Mayes received personal fees for being a conference speaker on the use of autoantibodies in connective tissue diseases for Medtelligence, Ganesh Raghu Grant/research support from: Ganesh Raghu is the principal investigator for IPF net studies and is a steering committee member for IPF net studies for the NIH., Consultant for: Ganesh Raghu is a consultant for Boehringer Ingelheim, Bellerophan, Biogen, BMS, Fibrogen, Gilead, Nitto, Revistan, Promedior, Sanofi, Veracyte and RocheGenentech; and a consultant and chair of the DSMB for Avalyn., Wiebke Sauter Employee of: Wiebke Sauter is an employee of Boehringer Ingelheim, Mannaig Girard Employee of: Mannaig Girard is an employee of Boehringer Ingelheim, Margarida Alves Employee of: Employee of
Boehringer Ingelheim, Emmanuelle Clerisme-Beaty Employee of: Emmanuelle Clerisme-Beaty is an employee of Boehringer Ingelheim, Veronika Kohlbrenner Employee of: Veronika Kohlbrenner is an employee of Boehringer Ingelheim, Masataka Kuwana Grant/research support from: Actelion, Consultant for: Chugai, Reata, GlaxoSmithKline, Bayer, Boehringer-Ingelheim, Corpus, CSL-Berling, Mochida, Speakers bureau: Actelion, Pfizer, Bayer, Nippon Shinyaku, Chugai, Oliver Distler Grant/research support from: Prof. Distler received research funding from Actelion, Bayer, Boehringer Ingelheim and Mitsubishi Tanabe to investigate potential treatments of scleroderma and its complications, Consultant for: Prof. Distler has/had consultancy relationship within the last 3 years with Actelion, AnaMar, Bayer, Boehringer Ingelheim, ChemomAb, espeRare foundation, Genen tech/Roche, GSK, Inventiva, Italfarmaco, iQvia, Lilly, medac, Medlmmune, Mitsubishi Tanabe Pharma, Pharmacyclics, Novartis, Pfizer, Sanofi, Sero dapharm and UCB in the area of potential treatments of scleroderma and its complications. In addition, he had/has consultancy relationship within the last 3 years with A. Menarini, Amgen, Abbvie, GSK, Mepha, MSD, Pfizer and UCB in the field of arthritides and related disorders DOI: 10.1136/annrheumdis-2019-eular.3995

\section{FRI0302 SAFETY AND EFFICACY OF RITUXIMAB BIOSIMILAR IN SYSTEMIC SCLEROSIS: AN ITALIAN MULTICENTER STUDY}

Corrado Campochiaro ${ }^{1}$, Giacomo De Luca ${ }^{1}$, Maria Grazia Lazzaroni ${ }^{2}$, Silvia Laura Bosello ${ }^{3}$, Maria De Santis ${ }^{4}$, Adriana Cariddi ${ }^{1}$, Carlo Selmi ${ }^{4}$, Elisa Gremese ${ }^{3}$, Paolo Airò ${ }^{2}$, Marco Matucci-Cerinic ${ }^{5}$, Lorenzo Dagna'. ${ }^{1}$ IRCCS San Raffaele Hospital, Unit of Immunology, Rheumatology, Allergy and Rare Diseases, Milan, Italy; ${ }^{2}$ Spedali Civili and University of Brescia, Rheumatology and Clinical Immunology, Brescia, Italy; ${ }^{3}$ Fondazione Policlinico Universitario A. Gemelli, Division of Rheumatology, Rome, Italy; ${ }^{4}$ Humanitas Research Hospital, Division of Rheumatology and Clinical Immunology, Milan, Italy, ${ }^{5}$ University of Florence, Division of Rheumatology AOUC, Florence, Italy

Background: recent data support the use of rituximab(RTX) in Systemic Sclerosis(SSc). RTX biosimilar(RTX-B) offers a more affordable option but its efficacy and safety have not yet been evaluated.

Objectives: To assess the safety and efficacy of RTX-B in SSc.

Methods: Data about SSc patients treated with RTX-B(1gr repeated after 2 weeks) and with a follow-up $\geq 6$ months were retrospectively collected from 5 Italian centres. Both SSc patients naïve to RTX(RTX-Bn) or already treated with $\geq 1$ course of RTX originator(RTX-O) and switched to RTX-B(RTX-Bs) were considered. A comprehensive assessment of disease features and organ involvement was available at baseline and at final follow-up for all patients. Non parametric tests were used.

Results: Data of 21 SSc patients( 20 female, mean age $50.5 \pm 11.8$ years) were collected;mean disease duration at RTX-B therapy was $7.6 \pm 4.8 \mathrm{yrs}$. Eleven patients(52\%) had diffuse cutaneous SSc(dcSSc), 12(57\%) were anti-topoisomerasel+, 5 anti-RNA-polymeraselll+ and 4 anti-centromere+ Twelve patients(57\%) were RTX-Bn and 9 RTX-Bs(43\%). In RTX-Bs patients, the median number of previous RTX-O courses was 3 (range 1 - 8). RTX was decided because of skin progression in $11(52 \%)$, interstitial lung disease(ILD) worsening in 9(43\%), arthritis in 6(29\%), myocarditis and myositis in 1 patient each. All patients had been previously treated with immunosuppressants: mycophenolate mofetil(MMF) 14(67\%), methotrexate(MTX) $7(33 \%)$, cyclophosphamide $6(29 \%)$, azathioprine $4(19 \%)$, tocilizumab and etanercept $1(5 \%)$ patient each. At RTX-B introduction, 14 (67\%) patients were on concomitant immunosuppressant: 10(48\%) MMF and $4(19 \%)$ MTX; 15 patients $(71 \%)$ were also on steroids(mean dose:3.1 $\pm 2.1 \mathrm{mg} /$ day). At 6 months after RTX-B treatment, a significant reduction of the modified Rodnan skin score(mRSS), DAS28 and erythrocyte sedimentation rate(ESR) was observed in the entire cohort $(p<0.001, p<0.028$, $p<0.003$, respectively); mRSS was significantly reduced also in RTX-Bn $(p<0.011)$ and RTX-Bs patients $(p<0.046)$ (Table 1$)$. No significant changes were observed for lung function tests. Only 1 RTX-Bs patient experienced a transient neutropenia 3 months after the $2^{\text {nd }}$ RTX-B infusion whilst also on MTX.

Conclusion: in agreement with previous data published on RTX-O, also RTX-B seem efficient in improving skin and joint involvement and in stabilizing lung function, either in RTX-Bn and in RTX-Bs SSc patients.

\section{REFERENCE:}

[1] JordanS,et al.AnnRheumDis.2015;74(6):1188-94. 
Table 1. Clinical, laboratory and lung functions tests of patients treated with RTX-B. Data expressed as mean \pm SD. FVC=forced vital capacity $(\%$ predicted $) ;$ TLC=total lung capacity $(\%$ predicted); DLCO=diffusion lung CO(\% predicted); DAS28=disease activity score 28 (3 RTX$\mathrm{Bn}, 3$ RTX-Bs) patients with arthritis);ESR(mm/1h).

\begin{tabular}{lccc}
\hline Overall & Time $\mathbf{0}$ & $\mathbf{6}$ Months & $\begin{array}{c}\mathbf{p} \\
\text { value }\end{array}$ \\
\hline mRSS & $11.8 \pm 9.3$ & $8.8 \pm 7.7$ & $\mathbf{0 . 0 0 1}$ \\
FVC & $89.7 \pm 21.1$ & $92.8 \pm 20.4$ & 0.089 \\
TLC & $86.3 \pm 19.4$ & $87.9 \pm 18.9$ & 0.219 \\
DLCO & $62.3 \pm 21.0$ & $60.7 \pm 18.8$ & 0.542 \\
DAS28 & $3.6 \pm 1.1$ & $2.2 \pm 0.9$ & $\mathbf{0 . 0 2 8}$ \\
ESR & $21.3 \pm 13.0$ & $16.9 \pm 9.7$ & $\mathbf{0 . 0 0 3}$ \\
RTX-Bn & & & \\
mRSS & $12.3 \pm 10.6$ & $9.2 \pm 8.3$ & $\mathbf{0 . 0 1 1}$ \\
FVC & $91.3 \pm 22.3$ & $95.3 \pm 18.8$ & 0.100 \\
TLC & 89.60 & $93.3 \pm 18.5$ & 0.172 \\
& \pm 21.16 & & \\
DLCO & $67.5 \pm 19.1$ & $64.3 \pm 15.4$ & 0.422 \\
DAS28 & $4.3 \pm 0.4$ & $2.1 \pm 1.1$ & 0.109 \\
ESR & $21.9 \pm 14.8$ & $17.4 \pm 11.2$ & $\mathbf{0 . 0 1 7}$ \\
RTX-Bs & & & \\
mRSS & $11.0 \pm 7.8$ & $8.2 \pm 5.9$ & $\mathbf{0 . 0 4 6}$ \\
FVC & $87.6 \pm 20.4$ & $89.4 \pm 23.1$ & 0.546 \\
TLC & $82.1 \pm 17.4$ & $80.1 \pm 18.0$ & 0.750 \\
DLCO & 56.00 & 56.33 & 0.799 \\
DAS28 & \pm 22.54 & \pm 22.49 & \\
ESR & $3.0 \pm 1.3$ & $2.4 \pm 0.9$ & 0.109 \\
\hline
\end{tabular}

Disclosure of Interests: Corrado Campochiaro Consultant for: Dr Corrado Campochiaro received consultation honoraria from Pfizer., Giacomo De Luca Consultant for: Dr Giacomo De Luca received consultation honoraria from Pfizer and SOBI., Maria Grazia Lazzaroni: None declared, Silvia Laura Bosello: None declared, Maria De Santis: None declared, adriana cariddi: None declared, Carlo Selmi Grant/research support from: AbbVie, Janssen, MSD, Novartis, Pfizer, Consultant for: AbbVie, Alfa-Sigma, Biogen, Bristol-Myrs Squibb, Celgene, Eli-Lilly, Janssen, Merck Sharp and Dohme, Novartis, Pfizer, Roche, Sanofi-Genzyme, UCB, Speakers bureau: AbbVie, Alfa-Sigma, Biogen, Bristol-Myrs Squibb, Celgene, Eli-Lilly, Janssen, Merck Sharp and Dohme, Novartis, Pfizer, Roche, Sanofi-Genzyme, UCB, Elisa Gremese Consultant for: AbbVie, BMS, Celgene, Janssen, Lilly, MSD, Novartis, Sanofi, UCB, Roche, and Pfizer, Speakers bureau: BMS, Speakers bureau: Roche, Speakers bureau: AbbVie, BMS, Celgene, Janssen, Lilly, MSD, Novartis, Sanofi, UCB, Roche, and Pfizer, Paolo Airò: None declared, Marco Matucci-Cerinic Grant/research support from: Actelion, MSD, Pfizer, BMS, Chemomab, Sanipedia, Speakers bureau: Actelion, BMS; MSD, Janssen, Lorenzo Dagna Consultant for: Prof Lorenzo Dagna received consultation honoraria from Abbvie, Amgen, Biogen, Bristol-Myers Squibb, Celltrion, Novartis, Pfizer, Sanofi-Genzyme, and SOBI.

DOI: 10.1136/annrheumdis-2019-eular.6961

\section{FRI0303 THE EFFECTS OF RIOCIGUAT ON RAYNAUD'S PHENOMENON AND DIGITAL ULCERS IN PATIENTS WITH DIFFUSE SYSTEMIC SCLEROSIS: RESULTS FROM THE PHASE IIB RISE-SSC STUDY}

Dinesh Khanna ${ }^{1}$, Yannick Allanore ${ }^{2}$, Christopher Denton ${ }^{3}$, Masataka Kuwana ${ }^{4}$, Marco Matucci-Cerinic ${ }^{5}$, Janet Pope ${ }^{6}$, Janethe de Oliveria Pena ${ }^{7}$, Kaisa Laapas ${ }^{8}$, Zhen $\mathrm{Yao}^{9}$, Melanie Hemmrich ${ }^{10}$, Oliver Distler ${ }^{11}$. ${ }^{1}$ University of Michigan, Ann Arbor, MI, United States of America; ${ }^{2}$ Cochin Hospital, Paris, France; ${ }^{3}$ University College London, London, United Kingdom; ${ }^{4}$ Nippon Medical School, Tokyo, Japan; ${ }^{5}$ University of Florence, Florence, Italy; ${ }^{6}$ University of Western Ontario, Ontario, Canada; ${ }^{7}$ Bayer US LLC, Whippany, NJ, United States of America; ${ }^{8}$ StatFinn Oy, Espoo, Finland; ${ }^{9}$ Bayer Healthcare Co. Ltd, Beijing, China; ${ }^{10}$ Bayer AG, Wuppertal, Germany; ${ }^{11}$ University Hospital Zurich, Zurich, Switzerland

Background: Riociguat is a soluble guanylate cyclase stimulator approved for treatment of pulmonary arterial hypertension associated with connective tissue disease. Through its vasodilatory and anti-remodeling properties, it was predicted that riociguat might relieve Raynaud's phenomenon (RP) attacks and reduce net digital ulcer (DU) burden in patients with diffuse cutaneous systemic sclerosis (dcSSc).

Objectives: We present exploratory endpoints from the RISE-SSc study (NCT02283762) on the effects of riociguat on RP and DUs in early dcSSc patients.

Methods: RISE-SSc was a Phase Ilb, multicenter, randomized, doubleblind, placebo-controlled study. Inclusion criteria were: SSc fulfilling ACR/
EULAR criteria, diffuse cutaneous involvement, disease duration $\leq 18$ months, and modified Rodnan skin score 10-22 units. Patients were assigned to placebo or riociguat individually adjusted from $0.5 \mathrm{mg}$ up to $2.5 \mathrm{mg}, 3$ times daily. Exploratory efficacy endpoints included 1) change in Raynaud's attacks from baseline to Week 14, assessed by: Raynaud's condition score; patient/physician assessment of RP; attack symptoms, attack duration, and average number of attacks per day; and 2) change in net DU burden from baseline to Week 52, assessed by ulcer count, ulcer burden, and visual analog score for patient-reported severity. Blood samples for exploratory evaluation of biomarkers were taken on Day 0 , Week 14 and for discontinuation before Week 14

Results: 60 patients were treated with riociguat and 61 with placebo None of the effects of riociguat on RP or DUs were statistically significant vs placebo. However, there was a greater relative reduction in attack duration, attack frequency, pain, numbness, tingling, and patient/ physician global assessment in the riociguat group vs placebo, from baseline to Week 14. Reductions in net DU burden were $-0.09 \pm 0.50$ for riociguat and $-0.08 \pm 1.47$ for placebo (estimated treatment difference: $0.11[95 \% \mathrm{Cl}:-0.38,0.17 ; \mathrm{p}=0.44]$ ) at Week 52. At Week 14, 2 patients in the riociguat group and 6 in the placebo group had developed new DUs. At Week 52, 5 and 12 patients, respectively, had developed new DUs. The total numbers of new DUs were 4 and 6 with riociguat and placebo, respectively, at Week 14 , and 12 and 65 , respectively, at Week 52 (Figure). Riociguat was associated with reductions vs placebo in serum sPECAM-1 $(p=0.004)$ and $C X C L-4 \quad(p=0.008)$, potentially indicating anti-vasculopathy properties of riociguat.

Conclusion: Riociguat did not produce statistically significant changes in DUs. Riociguat may reduce the development of new DUs in patients with early dcSSc and may favourably improve cytokine vasculopathy.
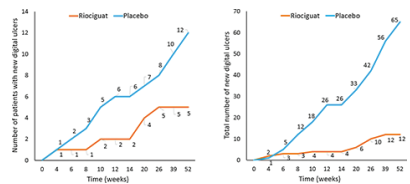

Figure. Development of new digital ulcers

Left: Number of patients with new digital ulcers

Right: Total number of new digital ulcers

New digital ulcers are defined as ulcers not existing at baseline.

Acknowledgement: Adelphi Communications Ltd, Bollington, UK provided medical writing support.

Disclosure of Interests: Dinesh Khanna Shareholder of: Eicos Sciences Inc, Grant/research support from: Bayer, BMS, Pfizer, Horizon, Consultant for: Actelion Acceleron, Arena, Bayer, BI, BMS, CSL Behring, Corbus, Cytori, GSK, Genentech/Roche, Galapagos, Employee of: Elcos Sciences, Inc, Yannick Allanore Grant/research support from: Inventiva, F Hoffman La-Roche, Sanofi, BMS, Pfizer, Consultant for: Actelion, Bayer, BMS, Boehringer, Roche, Sanofi, Christopher Denton Grant/research support from: GlaxoSmithKline, Inventiva, CSF Behring, Consultant for: RocheGenentech, Actelion, GlaxoSmithKline, Sanofi Aventis, Inventiva, CSL Behring, Boehringer Ingelheim, Bayer, Masataka Kuwana Grant/research support from: Actelion, Consultant for: Chugai, Reata, GlaxoSmithKline, Bayer, Boehringer-Ingelheim, Corpus, CSL-Berling, Mochida, Speakers bureau: Actelion, Pfizer, Bayer, Nippon Shinyaku, Chugai, Marco MatucciCerinic Grant/research support from: Actelion, MSD, Pfizer, BMS, Chemomab, Sanipedia, Speakers bureau: Actelion, BMS; MSD, Janssen, Janet Pope Consultant for: Eli Lilly and Company, Janethe de Oliveria Pena Employee of: Bayer, Kaisa Laapas Employee of: StatFinn Oy, partly insourced to Bayer, Zhen Yao Employee of: Bayer, Melanie Hemmrich Employee of: Bayer AG, Oliver Distler Grant/research support from: Prof Distler received research funding from Actelion, Bayer, Boehringer Ingelheim and Mitsubishi Tanabe to investigate potential treatments of scleroderma and its complications, Consultant for: Prof. Distler has/had consultancy relationship within the last 3 years with Actelion, AnaMar, Bayer, Boehringer Ingelheim, ChemomAb, espeRare foundation, Genentech/Roche, GSK, Inventiva, Italfarmaco, iQvia, Lilly, medac, Medlmmune, Mitsubishi Tanabe Pharma, Pharmacyclics, Novartis, Pfizer, Sanofi, Serodapharm and UCB in the area of potential treatments of scleroderma and its complications. In addition, he had/has consultancy relationship within the last 3 years with A. Menarini, Amgen, Abbvie, GSK, Mepha, MSD, Pfizer and UCB in the field of arthritides and related disorders DOI: 10.1136/annrheumdis-2019-eular.5755 